\title{
HISTÓRIA E LITERATURA: UM DIÁLOGO POSSÍVEL COM O ROMANCE PIUM DE ELI BRASILIENSE
}

\author{
HISTORY AND LITERATURE: A POSSIBLE DIALOGUE WITH THE PIUM \\ ROMANCE BY ELI BRASILIENSE
}

Recebido: 29/10/2021

Aprovado: $08 / 12 / 2021$
DOI: $10.18817 /$ rlj.v5i2.2696

Publicado: 22/12/2021

Maria de Fátima Oliveira ${ }^{1}$

Orcid ID: http://orcid.org/0000-0002-9519-8093

Larissa dos Santos Freitas ${ }^{2}$

Orcid ID: https://orcid.org/0000-0002-5853-3470

\begin{abstract}
Resumo: O presente artigo busca analisar a relação entre a História e a Literatura no romance Pium, do escritor Eli Brasiliense. O estudo tem como embasamento teórico autores que defendem ser esse diálogo viável e vantajoso para as duas áreas do conhecimento. Contudo, nem sempre essa relação foi um consenso, ficando a literatura à margem das fontes históricas por um longo tempo, mas este cenário foi modificado principalmente a partir da escola dos Annales, que passou a considerá-la importante para investigar com maior amplitude a história e a sociedade, devido a aceitação e inserção de novos objetos, novas abordagens e consequentemente com a aceitação de novas fontes, dando ênfase à História Cultural. A hipótese que se levanta é a de que o diálogo entre a História e a Literatura é muito profícuo na obra de Brasiliense e que por meio do romance Pium é possível conhecer aspectos econômicos, políticos e culturais da região no período.
\end{abstract}

Palavras-chave: História. Literatura. Garimpo. Pium. Norte goiano.

Abstract: This article aims to analyze the relationship between History and Literature in the novel Pium, by writer Eli Brasiliense. This paper is theoretically based on authors who claim that this dialogue is viable and advantageous for both áreas of knowledge. However, there hasn't always been a consensus on this matter, since literature has been on the fringes of history for a long time, but this scenario has changed mostly after the Annales School, which started considering it importante to investigate history and Society as the most ample means of investigating history and the Society mory broadly due to the acceptance and insertion of new subjects, new approaches, and consequently, the acceptance of new sources, giving the emphasis on the Cultural History. The hypothesis that arises is that the dialogue bethwen History and Literature is very fruitful in Brasilienses's work and that through the romance Pium it is possible to learn about economic, political and cultural aspects of the region in the period.

Keywords: History. Literature. Mining. Pium. North of Goiás.

\section{Introdução}

Eli Brasiliense é considerado um dos maiores romancistas goianos do século XX, nascido em Porto Nacional no ano de 1915, eternizou em sua obra importantes aspectos sobre o antigo norte goiano (hoje estado do Tocantins) e sobre Goiás. Podese dizer que o conhecimento sobre este extenso território se alargou com a obra de Eli Brasiliense. Nesse contexto, Pium, objeto de estudo desta pesquisa, é um romance

\footnotetext{
${ }^{1}$ Doutora em História pela Universidade Federal de Goiás (UFG). Docente do Curso de História e do Programa de Mestrado Interdisciplinar Territórios e Expressões Culturais no Cerrado (TECCER) da Universidade Estadual de Goiás (UEG). E-mail: proffatima@hotmail.com

${ }^{2}$ Graduanda do Curso de História na Universidade Estadual de Goiás (UEG); Bolsista PIBIC/CNPq. E-mail: larissasantosfreitas01@gmail.com
} 
histórico que prende a atenção do leitor e o convida a refletir sobre os problemas sociais que os moradores da região enfrentavam, pois o norte goiano era visto como abandonado pelo poder público. Neste romance, Brasiliense denuncia as mazelas locais por meio de sua brilhante narrativa, e a construção de seus personagens permite perceber as sensibilidades de uma época em que o lugarejo derramava cristal de quartzo, transformando um local pouco povoado em um conglomerado de pessoas vindas de todas as regiões do país a procura de riqueza desenfreada.

A análise se pauta no diálogo com teóricos que defendem o uso da literatura enquanto fonte propícia e enriquecedora da história com o romance de Eli Brasiliense, observando as diferenças inegáveis, o compromisso da história com o real, e o da literatura enquanto representação de um imaginário, de uma sociedade, ou de um contexto. Assim, o estudo tem como objetivo mostrar como ocorre a relação entre a História e a Literatura neste romance de Eli Brasiliense, buscando conhecer melhor o autor, sua obra e seu local de fala, investigando questões histórico sociais tanto por meio da história como da ficção.

Para melhor compreensão, o texto está dividido nos seguintes tópicos: uma discussão sobre a relação entre a História e a Literatura; um pouco da vida e obra de Eli Brasiliense; aspectos da história do norte goiano e a região garimpeira de Pium; e por último, uma análise detalhada do romance mostrando como as questões históricas estão entrelaçadas com a ficção no romance Pium.

\section{História e Literatura: uma relação profícua}

A relação entre a História e a Literatura tem se mostrado relevante para ambas as áreas do conhecimento, e a literatura tem sido vista por muitos historiadores como uma fonte rica por propiciar a percepção de aspectos que muitas vezes não são visíveis nos textos históricos, pois a literatura permite enxergar sensibilidades de uma época. Inicialmente, para a compreensão do uso da literatura como fonte histórica, é preciso voltar ao passado e entender que essa fonte de saber não era oficialmente considerada segura e fiel para a História. De acordo com Antônio Celso Ferreira (2009), na segunda metade do século XIX, quando a História se tornou uma disciplina acadêmica, o termo fonte passou a ser entendido como um sinônimo de documento e expressão de autoridade e verdade. 
Foi nessas circunstâncias que as fontes escritas, preferencialmente oficiais, ganharam o status de documentos verdadeiros para uma historiografia preocupada, sobretudo, com o encadeamento cronológico dos acontecimentos políticos nacionais. Nessa perspectiva, os textos literários, assim como outras fontes artísticas, não eram considerados documentos fidedignos para atestar a verdade histórica (FERREIRA, 2009, p. 63).

No século XX os historiadores dos Annales, entre eles Lucien Febvre e Marc Bloch, fizeram críticas a essa historiografia, colocando em pauta uma história problema, a fim de se entender a complexidade das experiências humanas. Dessa forma, passaram a dar ênfase aos processos sociais e econômicos, propondo uma maior amplitude no território do historiador, abrangendo campos de estudo antes deixados de lado, como o inconsciente, o cotidiano, a juventude, o mito, a infância, entre outros, incluindo a literatura.

De acordo com Sandra Jathay Pesavento (2003), nas décadas de 60 e 70 a literatura tinha um papel militante e engajado, um comprometimento com o social. E a história, tinha um perfil crítico com a missão de denunciar as injustiças sociais. Portanto, ambas serviam a uma causa. A autora afirma que atualmente, a aproximação entre as narrativas históricas e literárias podem ser entendidas "[...] como discursos que respondem às indagações dos homens sobre o mundo, em todas as épocas." (PESAVENTO, 2003, p. 32). Essa relação pode representar as expectativas, desejos, e até temores sobre a realidade. Isso pode ser compreendido como um fator primordial para a corrente historiográfica da História Cultural. Desse modo, ambas as áreas, embora sejam formas inegavelmente distintas, podem estar próximas para a compreensão da realidade ou para desvendar sentidos.

Apesar de estarem próximas, é preciso diferenciá-las e entender suas respectivas posturas. O texto literário para Pesavento (2003) é um importante apoio no entendimento da mentalidade de uma época, contudo ao entrecruzá-lo com outras fontes possibilita reforçar a autoridade de fala.

Já a literatura, nos indica Paul Ricouer, cria uma modalidade narrativa referencial ao mundo, com pretensão aproximativa. Não precisa comprovar ou chegar a uma veracidade, mas obter uma coerência de sentido e um efeito de verossimilhança. A rigor, História e a Literatura obtêm o mesmo efeito: a verossimilhança, com a diferença de que o historiador tem uma pretensão de veracidade (PESAVENTO, 2003, p. 37). 
Para além dessas diferenças, se o historiador estiver interessado no resgate da sensibilidade de um determinado contexto, ou melhor dizendo, na interação social entre os indivíduos, na maneira de pensar, ou ainda como os homens representavam a si próprios e o mundo a sua volta, a literatura pode ser uma fonte edificadora para seu trabalho, uma vez que ela é um registro importante de uma época. Permite que se observe o imperceptível, uma realidade sensível: "A literatura é o domínio da metáfora da escrita, da forma alegórica da narrativa que diz sobre a realidade de uma outra forma, para dizer além" (PESAVENTO, 2003, p. 40).

Para Valdeci Rezende Borges (2010), ao considerar uma obra literária para a compreensão de um conhecimento histórico, o historiador volta-se com um olhar abrangente para saber quem fala, de onde fala, e que linguagem o escritor utiliza. Essas são questões indispensáveis para tentar entender as suas condições históricas, o lugar social onde a obra foi produzida e as intenções do produtor.

Partindo desses pontos de vistas, um fator comum observado nesses autores, e principalmente em Pesavento, é o de como as obras literárias podem representar os anseios de uma época. Na obra do escritor Eli Brasiliense isso fica evidente, e como ressalta Borges, saber de onde fala e como fala o autor, ou melhor dizendo, em qual realidade social ele se insere é importante para melhor assimilar os conceitos históricos que a obra apresenta. Para o objetivo desse estudo é fundamental, portanto, adentrar nas vivências de Brasiliense para uma melhor compreensão de seu universo criativo.

\section{Vida e obra de Eli Brasiliense}

Em consonância com a cronologia da vida do autor na quinta edição do livro Pium, Eli Brasiliense nasceu em 18 de abril de 1915 em Porto Nacional, em um Tocantins que ainda fazia parte do território goiano. Filho de Jesuína Silva Braga e Bernardino Ribeiro, viveu sua infância na região sempre em contato com o caudaloso Rio Tocantins. No Colégio São Tomás de Aquino, teve seu primeiro convívio com a escola e com a escrita, desde pequeno familiarizou-se com a literatura francesa e portuguesa, e concluiu na mesma instituição de orientação dominicana, quando ainda adolescente, o curso de Humanidades.

Ainda jovem, Brasiliense saiu de seu município se aventurando por duas cidades históricas goianas: Corumbá e Cidade de Goiás, onde contraiu duas doenças, 
respectivamente, o tifo e a varíola. Em 1936 retorna para a região norte e torna-se professor do Grupo Escolar Pádua Fleury, localizado em Pedro Afonso (TO). Nessa mesma época exerceu também o ofício de jornalista. Dois anos depois transfere-se para Pirenópolis, onde leciona francês e português na Escola Normal Padre Gonzaga. Ademais, torna-se também secretário e contador da prefeitura. Para além de sua vida profissional, o autor encontra sua companheira de vida na mesma cidade, Luciana Fleury, e se casa aos 24 anos.

Embora tenha passado por inúmeras cidades goianas, construindo sua vivência e consolidando sua carreira, é na terra do chão vermelho, Goiânia, que ele vive o auge de sua vida pessoal e profissional. Em 1943 assume o cargo de funcionário do Departamento Estadual de Cooperativismo, ao mesmo tempo em que atua como professor, profissão que nunca abandonou. Passando por cargos importantes e lecionando por muitas escolas, Brasiliense se aventura por volta de 1945 em uma outra área, não muito longe daquelas que ele já dominava, a poesia. Mas escreveu por pouco tempo obras poéticas, embora, tal qual destacou Edival Lourenço (apud RODRIGUES, 2015), a poesia dele apresentava um estilo considerável, mas aos poucos foi perdendo gradativamente o espaço para a ficção, área que ele dominará alguns anos mais tarde.

Em 1949 nascia uma de suas mais célebres obras: Pium. Tal fato se comprova quando ele recebe um prêmio pela Bolsa de publicações Hugo de Carvalho Ramos. A partir daí o autor se entrega completamente à carreira de escritor. À primeira produção sucederam-se outras, e antes de lançar seu terceiro livro, foi eleito o terceiro presidente da Associação Brasileira de Escritores (ABE), que passou a se chamar União Brasileira de Escritores, (UBE), fundada em Goiás em 1945.

No ano de 1954 o público conheceu Bom Jesus do Pontal, romance que narra a destruição do lugarejo - núcleo mineratório do século XVIII - de mesmo nome, pelos índios e o início da formação de Porto Nacional. Em 1956 surgia Chão Vermelho, narrativa urbana que conta o nascimento e primeiras décadas da nova capital, Goiânia. Adentrou em 1957 na Academia Goiana de Letras, da qual foi presidente de 1961 a 1964. Com o romance Rio Turuna (1964), venceu o primeiro concurso literário da Universidade Federal de Goiás (UFG). Mesmo após a aposentadoria, Brasiliense não parou. Lançou em 1968 o livro de contos Irmão da noite; um ano depois Um Grão de Mostarda; em 1970, A morte do homem eterno (ensaios); quatro anos depois, $O$ Perereca, e em 1977, é lançado o romance Uma sombra no fundo do rio. 
De acordo com Yago Rodrigues (2015), e a cronologia da quinta edição de Pium: nos garimpos de Goiás, após uma vida agitada e intelectualmente rica, Eli Brasiliense falece em cinco de dezembro de 1998 com 83 anos de idade, acometido por uma doença incerta, e deixando como herança em suas obras um grande patrimônio do norte goiano advindo de sua brilhante carreira.

Pium, o primeiro grande romance lançado pelo autor, é objeto de análise do presente artigo. Retratando elementos cruciais como as características sociais e geográficas da região, o modo de vida da população local, seus usos e costumes, e a influência moderna que ia aos poucos ganhando espaço em Pium, o romance ajuda a compreender e resgatar a história regional e o fenômeno fundamental que movia a economia goiana no período em questão: os garimpos de Goiás no século XX. Brasiliense narra a efervescência do cristal na década de 1940 e sua valorização no cenário nacional e global sob o contexto da Segunda Guerra Mundial.

\section{O Norte Goiano e a história da região de Pium}

De acordo com Silva (2013) Goiás tem sua história marcada, entre outras coisas, pelos desbravamentos de bandeirantes, caçadores de índios e garimpeiros em busca de riquezas advindas do ouro e de outros minérios. A região se torna uma capitania em 1749, pois até esta data pertencia à capitania de São Paulo. $O$ antigo Norte Goiano, de acordo com Cavalcante (1990), possuía uma grande extensão correspondente a 44,8\% do estado de Goiás. A população se aproximava de 482.372 mil habitantes, que se distribuía por 60 municípios. Havia cinco grandes macrorregiões: a do Extremo Norte Goiano, Tocantínia de Pedro Afonso, Médio Tocantins Araguaia e Serra Geral de Goiás. Essa região pertenceu a Goiás, econômica, geográfica e politicamente até 1989 quando se tornou independente, assumindo uma identidade política e jurídica própria, passando a compor mais uma federação da república brasileira, se tornando o estado de Tocantins.

O processo de ocupação do Norte de Goiás se iniciou nas primeiras décadas do século XVIII com base na exploração aurífera. Ainda segundo a autora, a exploração das minas foi o ponto de partida para a formação dos primeiros núcleos de povoamento na região, por volta de 1730 , quando surgiram os primeiros arraiais. A exploração das minas se estendeu ao longo do século XVIII. Não obstante, a autora 
salienta que: "Outra atividade estimulou a ocupação econômica: a pecuária. O gado também abriu caminhos para o sertão do interior" (CAVALCANTE, 1990, p. 14).

Contudo, esse cenário começou a mudar: "Só percebemos que esse marasmo começa a ser superado quando, ao alvorecer o século $\mathrm{XX}$, a ferrovia penetra o sudeste goiano, dando início a todo um processo de alteração da estrutura socioeconômicas, política, e cultural de Goiás" (CAVALCANTE, 1990, p. 15). Apesar de a ferrovia ser um importante fator, não só para a modernização do estado, como também para a economia goiana, a ocupação econômica que se fazia presente, apresentou um desequilíbrio visível entre o Norte e o Sul de Goiás. Com a consolidação dessa expansão com base capitalista, houve uma tendência na diferenciação regional entre o norte e o sul, uma vez que havia uma concentração, nesta última região, de investimentos não apenas do capital privado, mas também públicos.

Segundo Silva (2013), por volta de 1940 houve uma grande ampliação e construção de rodovias que culminaram em um crescimento urbano acelerado. Além disso, a construção da nova capital era a esperança de um grande progresso para a região. Tais avanços trouxeram para o estado notoriedades na economia brasileira, com destaque para a região sul, tendo o Norte Goiano ficado em desvantagem com a ascensão que ocorria na região oposta.

Adentrando ao norte de Goiás, em uma localidade a oeste do município de Porto Nacional, havia uma região garimpeira, habitada apenas por moradores locais. De acordo com Paolini (2021), foi no ano de 1940 que esse lugarejo passou a ser conhecido devido às minas de cristais. Ainda segundo a autora, Pium foi "descoberto" quando Benedito Araújo, vindo dos garimpos de São José, estado de Minas Gerais, tomou conhecimento de uma rica região abundante em minérios próxima a Porto Nacional. Curioso sobre o assunto, dirigiu-se para lá e iniciou suas pesquisas, logo, descobriu que o local continha vastas jazidas de cristal, a notícia, portanto, se espalhou pelos donos de garimpos locais que iam à região, ambicionados pela riqueza.

Dessa maneira, iniciou-se o povoamento do arraial que recebeu inicialmente 0 nome de Piaus, segundo Silva (2013). Depois passou a se chamar Pium, em face da grande quantidade de um mosquito pequeno nativo da região com esse nome. Em pouco tempo o lugarejo que foi construído por garimpeiros locais, passou a se tornar um local populoso. Tendo em vista esse fato, e em consequência da constante migração para o povoado, moradores de garimpos próximos como o de Fundão e 
Cristalina, citados no romance de Brasiliense, além de pessoas vindas das grandes metrópoles São Paulo e Rio de Janeiro (como o médico Alcide, personagem de Brasiliense). Assim, houve um crescimento desordenado, bem como o surgimento dos problemas sociais que eram enfrentados pela população, como a pobreza e a falta de assistência básica.

Em um contexto de Segunda Guerra Mundial, o cristal de quartzo extraído de Pium e de outras regiões garimpeiras como Cristalina, Niquelândia, Cavalcante, entre outras, "[...] foi matéria prima muito importante para a economia brasileira, sendo usado em indústrias de alta tecnologia, fato esse que colaborou para que o Brasil fosse o maior exportador mundial de quartzo durante a Segunda Guerra Mundial." (CHULES, 2018, p. 9). Tal fato mostra a importância econômica do mineral para o Brasil e alta do preço do cristal, consequência para a então explosão da região que atraía muitos imigrantes.

É a partir dessa conjuntura que Brasiliense tece sua narrativa, de maneira leve e ímpar ele denuncia intrinsecamente as adversidades locais advindas do aumento populacional, aliado à pouca assistência do poder público e as penúrias notórias na vida de seus personagens muito bem construídos.

\section{Por dentro do romance Pium}

O sofrimento nos obriga a chamar esse homem eterno para junto de nós. Sua experiência nos consola, nos mostra novos caminhos, menos sinuosos e menos longos. O passado, porém, estava velho demais para mostrar novo caminho a Zé do Carmo, que era quase um cisco atirado pelo Tocantins ao campo, e que fora parar no pandemônio do garimpo (BRASILIENSE, 2006, p. 63).

Obra premiada, conforme visto anteriormente, Pium é publicado em 1949. O romance, carregado de uma linguagem goiana, nos leva a adentrar ao mundo do garimpo, conhecendo todas as mazelas e pequenas alegrias que a população garimpeira vivia. As histórias, as memórias, e o drama das personagens é peça fundamental para o enredo do romance, e através delas, é possível compreender as sensibilidades de uma época e de uma região.

Conforme os organizadores da edição especial do romance - que conta com Adovaldo Sampaio e Albertina Vicentini em seu conselho editorial - a quinta edição 
de Pium foi feita pelo Instituto Centro-Brasileiro de Cultura no ano de 2006. Essa edição surgiu a partir de um projeto do jornal $O$ Popular que visava realizar um balanço da literatura em Goiás, com o intuito de resgatar a literatura regional. Este projeto contaria com uma compilação de obras literárias de autores goianos considerados importantes para a história e a memória da região, como Hugo de Carvalho Ramos, Bernardo Élis, José J. Veiga, Eli Brasiliense, entre tantos outros escritores. As escolhas dos intelectuais levaram em conta a importância dessas obras como resgate de uma cultura pouco lembrada, ou simplesmente apagada da história, e que de alguma forma contribuíam ricamente para áreas tão amplas do saber, como a geografia e a história.

O romance de Brasiliense aborda elementos próprios dos garimpos de Goiás na década de 1940, características bem visíveis na história das regiões de Fundão, Cristalina e mais especificamente de Pium, onde o autor aprofunda-se no cotidiano dos garimpeiros, e a partir daí, se desenvolve a trama. O autor narra a vida de personagens típicos da região em que suas histórias estão interligadas, embora cada uma tenha suas particularidades. Na trama está viagem de Domingos à cidade de Anápolis (GO) para servir a FEB (Força Expedicionária Brasileira). O passageiro triste e mergulhado em suas próprias inquietações atravessa o arraial dentro de um caminhão Ford, sendo levado a seu passado pelas memórias pesarosas que marcaram sua vida naquele lugar. Silvestre é o motorista que silenciosamente o observa. É através desse cenário que a história começa a se desenrolar, no qual o livro é ambientado em dois momentos que se entrelaçam na narrativa. O primeiro é a saída de Domingos da região, passando pelas estradas do arraial. Ao mesmo tempo, o segundo momento ganha espaço, as histórias da região de Pium que vão sendo recordadas pelo autor e pelo próprio personagem. Estas embora sejam lembradas em flashes, seguem uma ordem cronológica, de fácil entendimento e percepção.

O cenário no qual a história se passa é descrito com ricos detalhes. Observase que naquela época, o povoado se organizava de maneira simples e precária, não havia saneamento básico e infraestrutura, o principal foco naquele instante eram os garimpos e suas provenientes riquezas. Os moradores residiam em singelas palhoças, geralmente baixas e de chão batido, em que as portas eram improvisadas com panos. Era comum ver nas ruas pessoas deitadas, doentes, gemendo e cobertas mesmo com o calor estridente. Vítimas de doenças que matavam aos poucos: malária, tuberculose, verminoses, dentre outras. O clima predominantemente seco e quente 
traçava a aridez vista no chão. Era uma terra difícil de se cultivar. Cavalos, burros e gados também compunham o cenário da região, magros e desnutridos procuravam em meio ao capim seco, alguma fonte de energia para mantê-los em pé. O típico clima do cerrado brasileiro deixava suas marcas na época da seca, e o que salvava os moradores dessa penúria eram os rios Tocantins e Araguaia, metaforicamente, quase um oásis em meio ao deserto. Além de compor a beleza nativa da região, eram também importantes para a economia local, transporte e sobrevivência da população.

Ressalta-se que nesta obra umas das questões mais trabalhadas pelo autor é a construção de seus personagens. Suas características e vivências fazem-nos adentrar ao enredo da história percebendo seus anseios e angústias. A protagonista Ritinha é um exemplo. Moça simples e inocente, educada rigorosamente pelo pai Zé do Carmo e sua mãe Sá Zefa, começa a se afligir por questões levantadas por um sertanejo rústico com características machistas e convincentes, como a maneira de se vestir e a sensualidade ainda perdida na singeleza da moça. Rolinha olha-a maliciosamente na loja de Domingos, oferece-lhe presentes e bugigangas a fim de conquistá-la. A partir daí, Ritinha se inquieta pensando na maneira que se vestia e comparando-se as mulheres que vinham das cidades grandes. O principal motivo de sua inquietação eram os constantes olhares libidinosos com que o sertanejo a fitava.

Zé do Carmo é um garimpeiro simples e com uma vida penosa, e assim como todos os garimpeiros locais sofria pela exaustão causada pelo trabalho árduo e contínuo. Um pai de família empenhado em trazer sustento à sua casa. Ele tinha um passado bem característico aos garimpeiros de Pium, era barqueiro no Rio Tocantins, vivia da pesca, se aventurando pelas águas caudalosas desse rio tão importante para a população. Já foi também lavrador, queria viver do sustento da terra, mas elas eram improdutivas e o fez abandonar a tarefa. Como um dos tantos trabalhadores locais foi movido pela agitação dos garimpos, até se tornar de vez um garimpeiro. Sua mulher Sá Zefa impressionava pela firmeza e capacidade de não desmoronar em meio a situações difíceis. Era um poço de calmaria e fortaleza.

Domingos é dono de uma lojinha muito frequentada na região central do povoado, o estabelecimento tem uma quantidade variada de itens como cachimbos, cigarros, vinhos baratos, tecidos, chapéus, brincos, e outros inúmeros objetos. Entretanto, mesmo casado com Helena, jovem mulher descrita por Brasiliense como elegante, educada e acolhedora, Domingos acaba se envolvendo com uma prostituta. 
Outro protagonista ilustre é o chofer Silvestre. Homem de muita vivência, dedica sua vida às estradas de Goiás, levando e trazendo passageiros e histórias. De uma total empatia e senso de justiça, conhecia bem as mazelas da população. Silvestre aparece a todo momento na narrativa, e tenta ofuscar com seu bom humor e alto-astral sua própria chateação e descontentamento com a penúria local. É personagem chave para o desenrolar da trama.

\title{
Diálogos entre a História e a Literatura em Pium
}

Vimos anteriormente que o lugar de fala de Brasiliense é Goiás, incluindo seu antigo norte, hoje Tocantins. Vivendo nesta região e atuando como professor, jornalista, funcionário público e escritor, pode-se compreender que conhecia sobre o que estava produzindo, pois através de pesquisas sobre o local, percebe-se que o contexto da época mostrado em sua ficção é bastante coerente com a história, como abordado a seguir.

Bourdieu (apud BORGES, 2010, p. 97) salienta que a recepção de uma produção pela sociedade ajuda a ter uma noção do campo intelectual e a elucidar a própria configuração da historicidade na obra, em outras palavras, as ideias de um autor podem ser postas em circulação dentro de um contexto ou de relações socioculturais. Ainda para o autor,

\begin{abstract}
Essa noção remete ao lugar de onde fala e em que se insere o autor, literato ou não, assim como outros escritores que o cercam; lugar circunscrito e estruturado ao redor das posições que esses produtores culturais ocupam na sociedade e no meio intelectual, no qual estabelecem relações entre si e com outros campos que constituem a vida social; lugar marcado pelos jogos de poder e vinculado com o campo político (BORGES, 2010, p. 97).
\end{abstract}

Perceberemos então que no romance Pium, a relação entre muitos campos sociais se faz presente, quando ele retrata, por exemplo, a miséria do lugarejo, o drama das personagens, como se expressavam sobre as questões sociais e políticas, o senso crítico, ou a falta deste sobre as problemáticas que eles vivenciavam, e sobre como o governo local e as autoridades lidavam com isso. Vimos que a literatura registra e expressa aspectos múltiplos do complexo. Continuamente veremos que o olhar histórico e simbólico de Pium se manifesta na obra de Brasiliense, uma vez que ela é uma reflexão sobre o que existe e uma projeção do que poderá vir a ser. Portanto, diante da narrativa de Brasiliense, da composição de suas personagens, de 
suas vivências, e do cenário sondado por ele, é possível perceber questões sociais, culturais e históricas abordadas no romance, o que mostram que neste caso, o diálogo entre a Literatura e a História é frutífero. Sendo assim, a seguir destacamos como as temáticas da pobreza, da alimentação, da representação da mulher, da vida dos garimpeiros, entre outras são abordadas no romance.

Em primeiro lugar, o cenário apresentado em Pium reforça o contexto da exploração mineral e o discurso de abandono da região Norte pelo governo, como evidenciados pela historiografia. Tal questão é abordada por Ana Motter (2010) que explica como se deu o processo de dinamismo social e econômico ao longo da história do Tocantins, além da relação da região com a extração de minérios desde o século XVIII. Passada essa fase aurífera, já no século XIX a região norte goiana enfrentou uma grave crise econômica. De acordo com a autora: “[...] essa sociedade [...] caracterizava-se por ser pouco integrada aos mercados regional e nacional e por ser pouco estratificada socialmente" (PALACIN, apud MOTTER, 2010, p. 22). Dessa forma, bem como a autora analisa, na sociedade do antigo norte goiano havia os mais diversos graus de pobrezas. Além dessa problemática, fica claro que a comunicação da região com as demais cidades do estado era dificultada e isso acontecia porque as estradas eram de difícil acesso, principalmente a que ligava a região à então capital Vila Boa. Assim sendo, o transporte acontecia tanto pelo Rio Tocantins quanto por terra, ambas difíceis e demoradas, tendo melhores condições apenas no século XX com o advento das rodovias.

Segundo Cavalcante (1999), houve uma intervenção estatal por parte do governo federal por volta da década de 1940 no estado, com a intenção de dinamizar a agricultura, através de um projeto de colonização agrícola, entretanto, esse projeto ficou restrito somente à região Centro-sul do estado:

A maior concentração de lavouras, com uma produção a nível comercial, estava nas regiões sul e sudoeste [...], enquanto isso, toda a região norte e nordeste do estado permanecia com uma economia assentada basicamente na pecuária - de 'péssima qualidade' - e uma agricultura com uma produção a nível de subsistência. (CAVALCANTE, 1999, p. 19).

Nesta mesma década, de acordo com o apresentado por Brasiliense no romance Pium, o local estava repleto pela efervescência do garimpo de cristal de rocha, e nesse cenário as dificuldades enfrentadas pela população, são elementos perceptíveis e evidenciados constantemente em sua narrativa, principalmente no que 
se refere à pobreza: "Pedaço de terra pedregosa e improdutiva esquecido nos sertões de Goiás." (BRASILIENSE, 2006, p. 21). Além desse aspecto, nota-se que a área do garimpo ficava em zona rural, sem energia, escolas, postos de saúde e demais assistências básicas. Morando em palhoças os moradores da região eram "[...] desamparados, sem assistência de qualquer espécie, inexpressivos, num abandono total." (BRASILIENSE 2006, p. 22). A multidão "faminta e nômade" vinda de todas as regiões do Brasil, especialmente das grandes metrópoles São Paulo e Rio de Janeiro, ajudava a culminar o cenário de pobreza no lugarejo, dessa forma o arraial crescia como "leite fervendo". Esse fator leva a uma outra problemática, a falta de controle da natalidade, pois as famílias sertanejas tinham muitos filhos, e geralmente não havia comida suficiente para alimentá-los: Brasiliense menciona que as crianças andavam "descalças e maltrapilhas".

Pobreza e ambição andavam juntas, e foram frequentemente exploradas por Brasiliense. Pode-se observar que os garimpeiros sabiam e sentiam as consequências do desejo de riqueza e a ganância pelo elemento principal do garimpo, mas "garimpo só não dá camisa é pra garimpeiro" (BRASILIENSE, 2006, p. 14), subentende-se que quem se beneficia com a exploração são os donos de garimpo.

Como é próprio das zonas de garimpos, a região atraía ambiciosos de todos os lugares. Os garimpeiros eram ainda enfeitiçados "[...] pela esperança de fortuna, sem muitas vezes saber que cavava a própria sepultura” (BRASILIENSE, 2006, p. 19). Ressalta-se ainda que o cristal era o que movia a economia local, logo, a produção da lavoura caía devido à alta procura pelo elemento e a dos próprios trabalhadores pelos garimpos, na esperança de um serviço mais rentável.

Por meio do romance pode-se compreender muito da cultura e tradição local do período. A religião predominante era a católica, e a devoção à Nossa Senhora do Carmo movia a fé dos garimpeiros. Sob esse aspecto religioso, ressalta-se a crença sobre aparições de assombrações de garimpeiros mortos nos arredores dos seus locais de trabalho, consequência da vida sofrida e do serviço exaustivo que causavam mortes frequentes. Outro elemento destacado pelo autor são as festas de "forrobodó" ao som da famosa sanfona. O povo animado bebia e dançava bastante até o amanhecer do outro dia. Era também uma maneira de aliviar o sofrimento cotidiano.

Ao tratar da alimentação, muitos produtos típicos aparecem na rotina dos personagens: a gordura de porco, o torresmo com farinha, a rapadura, a jacuba (uma espécie de papa de farinha de mandioca preparada com mel, açúcar ou rapadura, a 
que se acrescenta, por vezes, leite ou cachaça) e o café, de costume, usado "requentado". Vale ressaltar ainda que, a fome se fazia presente e a comida era racionada e "desvitaminizada", além disso, as carnes tinham preços exorbitantes. Os garimpeiros raramente comiam em casa, pois tinham de se alimentar rapidamente para retornar à labuta. Outro fator típico da tradição local era o uso dos remédios naturais, o "quinino", extraído da quina, planta medicinal amarga usada para tratar a malária, e a salmoura, solução de água e sal usada para a cicatrização de ferimentos eram usados habitualmente.

A mulher é retratada principalmente pela personagem Ritinha, a qual o autor descreve muito bem. A construção dessa personagem representa a maneira de como as mulheres viviam e eram tratadas em sociedade naquele local na visão de Brasiliense. Pode-se observar inúmeras concepções a partir de sua vivência. Outrora mencionado, a moça vê-se envolvida e persuadida pelo sertanejo Rolinha, que lhe assedia constantemente, oferecendo-lhe presentes. A inocência das moças e de seus pais era visível em meio a um cenário de "depravação, corrida para o dinheiro e de completa alucinação" (BRASILIENSE, 2006, p. 40), ainda se fazia presente.

Os rótulos sobre as mulheres e a fraqueza feminina também são abordados, e de acordo com o romance, o machismo era habitual, inclusive com o inusitado costume de os homens castigarem suas mulheres quando chegavam de viagens, com o intuito de mostrar "quem mandava" e evitar traições. Brasiliense (2006) narra ainda sobre a quantidade de bordéis que havia na região de Pium e nas cidades de seu entorno. O termo "mulheres baratas" era usado para designar as prostitutas. Em um cenário onde a alternativa para grande parte dessas mulheres era a prostituição, a consequência era uma grande falta de esperança em relação ao presente e ao futuro, como bem representada na fala da personagem Totica, dona de uma pensão: "Já tive muita dó de gente como eu, mas não adianta. Nossa vida é desse jeito mesmo. Ou fica velha no canto, passando fome, em molambo, ou abre um bordel para viver da infelicidade das outras." (BRASILIENSE, 2006, p. 105). Se esse não era o destino para algumas, outro era certeiro: o papel da mulher como dona de casa. Além disso, culturalmente, a traição dos homens às suas esposas era considerada normal, os prostíbulos eram sempre lotados de clientes.

Outro aspecto percebido no romance é a maneira como as notícias chegavam ao lugarejo. O jornal, o rádio e o transporte terrestre eram os meios de comunicação possíveis naquela região, embora fossem poucos os moradores que tinham acesso a 
eles: "A sindicalização é o caminho mais curto para se atingir um padrão de vida mais humano! Essa tirada deveria ser de algum jornal. Não importava. Quem iria ler jornais naquelas bibocas?" (BRASILIENSE, 2006, p. 68). Essa situação começou a mudar com a ideia do personagem Januário que pretendia trazer um jornal local para a região: "Quem voltava ao passado era como quem procurava uma joia num montão de pedras [...] lá aparecia o tio Januário, trazendo para Porto Nacional uma tipografia, a fim de montar um jornal." (BRASILIENSE, 2006, p. 88). Aos poucos o meio de comunicação gerava interesse: "No dia da circulação do primeiro número de $O$ Libertador todo mundo o queria ler. Quem era analfabeto pedia a outra pessoa letrada para o ler em voz alta. O jornalzinho se afundara pelas fazendas, pelas roças, alastrando-se pelas cidades vizinhas" (BRASILIENSE, 2006, p. 88).

O rádio era mais comum em outras cidades do estado, onde a modernização já havia chegado. Quando Domingos partiu para Anápolis para servir na Segunda Guerra Mundial, depois da morte de sua esposa, o objeto que funcionava por meio das pilhas estava presente no quarto do hotel que abrigava os soldados: "No refeitório o rádio do hotel estava ligado. O noticiário da guerra prendia todas as atenções. As forças Expedicionárias Brasileiras já haviam estabelecido contato com os nazistas." (BRASILIENSE, 2006, p. 155). Além disso, os Caminhões e as caminhonetes além de meio de transporte, eram também um meio de comunicação, uma vez que as notícias das cidades grandes e do mundo viajavam e chegavam na região pelo relato dos choferes e de seus passageiros.

A falta de oportunidades e o descaso com a população, refletidas na questão educacional, também ganham espaço na ficção, mostrando certa apatia da população local. Em um trecho Brasiliense denuncia esse fato: "Assim era aquela gente. A ignorância Ihe transtornava a mente com um terrível fatalismo, uma incapacidade de reação fora do comum." (BRASILIENSE, 2006, p. 22). Mais à frente o autor menciona a falta de auxílio e motivação para melhora de condição de vida dos moradores, ou de novas oportunidades, que não sejam o trabalho exaustivo do garimpo e da terra improdutiva. No trecho a seguir Brasiliense apela para um tom mais irônico, chamando a atenção do leitor para as condições em que eles viviam, e a negligência das autoridades:

Talvez nem ao menos tivessem sido recenseados. Quem se meteria naquelas bibocas para ganhar quarenta centavos por cabeça para incluir na população brasileira gente doente e miserável? O esforço daquela gente se anulava ante a ruindade do meio e a falta de auxílios para empreendimentos 
atrevidos, compensadores e capazes de melhorar a sua condição de selvagens (BRASILIENSE, 2006, p. 22).

$\mathrm{Na}$ falta de uma educação formal a essa população, o conhecimento chegava em forma de contato com pessoas que vinham das grandes metrópoles. Silvestre, em conversa com seu passageiro, um médico carioca, demonstra esse fato: "Outro dia viajei com o padre Manuel e ele me contou que no tempo de César havia uma lei qui mandava jogar de riba duma serra todo minino qui nascesse imprestável, com defeito no corpo." (BRASILIENSE, 2006, p. 49). A consequência dessa falta de escolaridade gerava uma descrença sobre o futuro, a sequência do diálogo marcante entre Silvestre e o médico demonstra esse fato: "Pai sempre me dizia que ainda ficava rico pra me mandar pro estudo, pra ser engenheiro [...] o que adiantou? Mataram ele e eu não passo hoje de chofer. $\mathrm{O}$ fato é qui eu reviro esse caminhão véio de riba pra baixo. Qualqué máquina de carro é comigo. Mais a gente não passa disso" (BRASILIENSE, 2006, p. 49). Fica claro nesse trecho que a falta de oportunidade mudava o destino do povo. Raras vezes eles conseguiam sair da região e ganhar a vida lá fora, o personagem Januário foi uma dessas exceções, ele conhecia o pesar da população, e por isso buscava por justiça social.

Outra temática que pode ser analisada no romance é a morte. Ao tratar das mortes no garimpo, o autor ressalta que não havia enterro decente aos garimpeiros, eram jogados em valas e os colegas não podiam acompanhar, pois o ritmo de trabalho nos garimpos era intenso, e "A voz de alerta para receber os blocos era contínua e ritmada" (BRASILIENSE, 2006, p. 52). Para além disso, a maioria deles desconheciam suas raízes: pais, mães e avós. Carregavam em suas lembranças um passado sofrido e a esperança de um futuro melhor. Esse passado estava muitas vezes ligado às suas antigas profissões, como era o caso dos barqueiros do Rio Tocantins, em um momento da história esse fato é lembrado por alguns personagens:

Zé do Carmo não conciliava o sono [...] lembrava-se de tempos longínquos, quando era bem jovem. Como tinha sido bom o seu tempo de barqueiro! Forte, peito largo, bom no remo e no varejão, batuta numa cuia de jacuba! Tu com essa peitaria e esse muque vai longe, rapaz! - dizia-lhe o velho Romão, um dos mais afamados pilotos da zona do Tocantins (BRASILIENSE, 2006, p. 59-60). 
Para assimilar os fatos ocorridos na cidade garimpeira de Pium, é preciso entender o que estava se passando no cenário nacional e mundial. No Brasil, na década de 40 a população vivia sob a ótica do Estado Novo instituído por Getúlio Vargas em 1937, depois de dissolver o congresso e as assembleias legislativas, ordenar o fechamento dos partidos, passar a perseguir seus opositores e outorgar uma nova constituição. Tudo isso acontecia sob o contexto da Segunda Guerra Mundial. Sobre esse último fator vale ressaltar a importância do cristal de quartzo, extraído de Pium e de outras regiões garimpeiras como Cristalina de Goiás, para o Brasil em um período de guerras, visto que ele foi "matéria prima muito importante para a economia brasileira, sendo usado em indústrias de alta tecnologia, fato esse que colaborou para que o Brasil fosse o maior exportador mundial de quartzo durante a Segunda Guerra Mundial" (CHULES, 2018, p. 9). No romance, esse fato é mencionado por Brasiliense:

\footnotetext{
Quando o mundo sentiu apavorado o peso da bota nazista, e experimentou no lombo o cutucar da espora da opressão, ouviu-se um grito quase angustiado, um grito, porém, salpicado de confiança: "Cristal! Dêem-nos cristal, por qualquer preço!" Para aquela terra inculta e má, perdida nos ermos de Goiás, as vistas do mundo se voltaram esperançosas. Ali havia cristal feito praga (BRASILIENSE, 2006, p. 23).
}

Portanto, vale ressaltar que a obra de Eli Brasiliense é uma importante fonte para compreender a história da região de Pium, usando de uma linguagem típica da região, nos leva ao cotidiano do garimpo de Pium e nos faz entender os usos e costumes daquela população, bem como a estrutura social e suas problemáticas que surgem em um contexto "de corrida para o dinheiro, e de completa alucinação" (BRASILIENSE, 2006, p. 40).

\section{Considerações Finais}

Pela análise pode-se constatar que a Literatura pode ser uma rica fonte para a investigação histórica. A partir dela podem ser feitas analogias entre a ficção e o fato histórico, buscando compreender o cotidiano de uma região e sociedade, levando em consideração as perspectivas culturais de um determinado contexto. Isso se tornou visível por meio da leitura e catalogação das questões encontradas no romance Pium, entrelaçadas com textos históricos que abordam a região. 
Vale ressaltar ainda que, uma obra nunca é estática, ou singular, ela pode conter informações plurais e interpretações múltiplas, e Pium é uma dessas obras. Brasiliense, indubitavelmente se inseriu na realidade histórico-social de Pium, dialogando e produzindo uma representação, por meio de suas vivências e conhecimento da região e dos moradores, transformando essa realidade em uma ficção que transborda em verossimilhança.

Através dessa pesquisa pode-se observar no romance a escrita, a estética, a linguagem e as convenções usadas pelo escritor, além de entender a mentalidade de uma época dentro de um contexto abarcado pela ambição, pobreza, e tradição local. Conheceu-se as angústias das personagens que enfrentavam a fome, a miséria, a pobreza e o abandono, típicas de uma povoação de garimpo.

O diálogo entre a História e a Literatura, tendo como foco o romance Pium, permitiu trazer as sensibilidades para a História e enriquecer o conhecimento sobre 0 antigo norte goiano, sobretudo, sobre a zona garimpeira e a cidade de Pium. Assim, pode-se afirmar que o romance de Eli Brasiliense é uma importante fonte de pesquisa e investigação histórica, pois contribui de modo ímpar para um melhor conhecimento da história regional, sendo possível conhecer aspectos econômicos, políticos e culturais da região no período abordado.

\section{Referências}

BORGES, Dr. Valdeci Rezende. História e Literatura: algumas considerações. Revista de Teoria da História. Ano 1, Catalão, v. 1, n. 3, p. 94-109, 03 jun. 2010. Disponível em: https://www.revistas.ufg.br/teoria/article/view/28658. Acesso em: 10/10/2021.

BRASILIENSE, Eli. Pium. 5. ed. Goiânia: ICBC, 2006.

CAVALCANTE, Maria do Espírito Santo Rosa. O movimento separatista do Norte de Goiás (1821-1982). 1990. Dissertação (Mestrado em História) - UFG, Goiânia, 1990.

CHULES, Juliana Sousa Ferreira. O mineral que ganhou a guerra: a exploração do cristal de rocha na cidade de cristalina (go). 2018. 33 f. TCC (Graduação) - Curso de História, Universidade de Brasília, Brasília, 2018. Disponível em: https://bdm.unb.br/bitstream/10483/22855/1/2018_JulianaSousaFerreiraChules_tcc.p df. Acesso em: 16/10/2021.

FERREIRA, Antônio Celso. A fonte fecunda. In: PINSKY, Carla Bassanezi; LUCA, Tania Regina de (Org.). O Historiador e Suas fontes. São Paulo: Contexto, 2009.

MEDEIROS, Enderson. Folha de Goyaz: o jornal e o seu tempo. In: ALCAR 2015, 10., 2015, Porto Alegre. 10ํEncontro Nacional de História da Mídia. Porto Alegre: Ufrgs, 2015. 
p. 1-17. Disponível em: http://www.ufrgs.br/alcar/encontros-nacionais-1/encontrosnacionais/10o-encontro-2015/gt-historia-da-midia-impressa/folha-de-goiaz-o-jornal-eo-seu-tempo/. Acesso em: 18/2021.

MOTTER, Ana Elisete. Representações da identidade do Tocantins na literatura e na imprensa. Tese (Doutorado) - Curso de História, Unidade Acadêmica de Pesquisa e Pós-Graduação, Universidade do Vale do Rio dos Sinos Unisinos, São Leopoldo, 2010. Disponível em: http://www.repositorio.jesuita.org.br/handle/UNISINOS/2185. Acesso em: 24/05/2021.

PAOLINI, Maria Francisca Pereira dos Santos. Tudo sobre Pium Estado de Tocantins. Disponível em: https://www.cidadesdomeubrasil.com.br/to/pium. Acesso em: $21 / 10 / 2021$.

PESAVENTO, Sandra Jatahy. O mundo como texto: leituras da História e da Literatura. In: Revista História da Educação. Vol. 22 n. 14. Pelotas: Universidade de Pelotas, 2003, p. 31-45. Disponível em: http://seer.ufrgs.br/index.php/asphe/article/view/30220/pdf Acesso em: 27/05/2021.

RODRIGUES, Yago. Eli Brasiliense, o centenário que se fez conhecido pelos "garimpos de Goiás". Jornal Opção: 45 anos. Goiânia, p. 1-1. 11 abr. 2015. Disponível em: https://www.jornalopcao.com.br/opcao-cultural/eli-brasiliense-o-centenario-quese-fezconhecido-pelos-garimpos-de-goias-32670/. Acesso em: 10/03/2021.

SILVA, Rosemeire de Souza Pinheiro Taveira. Um estudo das expressões lexicalizadas na obra Pium, de Eli Brasiliense. 2013. 169 f. Dissertação (Mestrado) Curso de Letras, Universidade Federal de Goiás, Catalão, 2013. Disponível em: https://repositorio.bc.ufg.br/tede/handle/tede/3838. Acesso em: 20/10/2021. 